\title{
LAS SENSACIONES DEL CAUTIVO, PSICOLOGÍA Y REACCIONES DE LOS ESPAÑOLES ANTE EL CAUTIVERIO EN EL SIGLO DE ORO
}

\author{
POR
}

Miguel ÁNGel de BUNEs IBARRA

CSIC-Madrid

\section{RESUMEN}

Acercamiento a la psicología de los españoles que son capturados por los corsarios norteafricanos en los siglos XVI y XVII. En estas páginas se analiza las diferentes maneras de aftontar el cautiverio hispano en el Magreb, haciendo especial insistencia en los testimonios que se conservan de los eclesiásticos capturados.

\section{Abstract}

Approaching to the psicology of the Spaniards captured by the Northafrican corsairs in the XVlth and XVIth Centuries. These pages analyse different ways of facing Spanish captivity in Magreb, focusing on the conserved testimonies of Eclesiastical captives.

\footnotetext{
A las orillas del mar,

que con su lengua y sus aguas,

ya manso, ya airado, llega

del perro Argel las murallas,

con los ojos del seseo

están mirando a su patria

cuatro míseros cautivos

que del trabajo descansan,
} 
$\mathrm{y}$ al son de ir y volver de las olas en la playa, con desmayados acentos esto lloran y esto cantan: ¿Cuán cara e $e^{(e r)} s$ de haber, oh dulce España! Tiene el Cielo conjurado con nuestra suerte contraria nuestros cuerpos en cadenas, y en gran peligro las almas. ¡Oh si abriesen ya los cielos sus cerradas cataratas, ya en vez de agua aquí lloviesen pez, resina, azufre y brasas! ¡Oh si se abriese la tierra, y escondiese en sus entrañas tanto Datán y Virón, tanto brujo y tanta maga! ¿Cuấn cara e ${ }^{(\text {re) }}$ s de haber, oh dulce España !

Este romance, incluido en la jornada segunda de Los baños de Argel de Miguel de Cervantes ${ }^{1}$, resume algunas de las sensaciones y sentimientos de los españoles cautivados por los musulmanes en el Siglo de Oro que se aproximan a las playas de la ciudad magrebí para añorar las tierras españolas. La cautividad en la época de los Austrias se relaciona invariablemente con el enfrentamiento entre la Cristiandad y el Islam en el mundo mediterráneo y trae implícito, además de la falta de libertad, el alejamiento de los límites de la Península Ibérica y los duros trabajos que apareja vivir entre «la paz y la guerra ${ }^{2}$. El escaso interés que ha despertado el cautiverio en los siglos XVI y XVI, mejor conocido por su faceta literaria y por el trance sufrido por algunos de los

1 Miguel de Cervantes, Los baños de Argel. Pedro de Urdemalas, Edición de Jean Canavaggio, Madrid, Taurus, 1992, Jornada Segunda, ver. 514-539, pp. 159-160.

2 «Mi padre era de Ronda

y mi madre de Antequera;

Captiváronme los moros

Entre la Paz y la guerra

$Y$ lleváronme a vender

A Vélez de la Gomera» Durán, Romancero general, núm. 258

Proyección internacional de la iglesia hispana

Hispania Sacra 51 (1999) 
escritores españoles del periodo ${ }^{3}$ que por cuestiones estrictamente históricas, es una consecuencia directa del relativo desinterés que ha supuesto el conocimiento de las circunstacias de la política española en el Mediteráneo y su enfrentamiento con otomanos y sa'díes. El cautivo cristiano en tierra musulmana, como la política en este mar, se ha quedado marginado en las revisiones historiográficas modernas sobre los diferentes reinados de los Austrias españoles. El aumento del número de cautivos coincide con la etapa en la que la política hispana es menos activa en el «mar interior», según la definición de $F$. Braude $^{4}$, generalizándose el corso como actividad económica y forma de vida de algnas de las ciudades de este entomo ${ }^{5}$.

En el siglo XVI se produce un cambio cualitativo en torno al cautiverio. Hasta el final de la conquista del reino de Granada el apresamiento de cristianos y musulmanes estaba relacionado con la guerra intestina, la «cruzada interior ${ }^{6}$ y seguía muchas de las manifestaciones de la guerra de fronteras que se había mantenido a lo largo de la Edad Media ${ }^{7}$ en los límites de la Península Ibérica. En los primeros años de la nueva centuria se mantienen los esquemas que se pueden referir hasta ese momento, siendo los almotacenes de diversa procedencia los encargados de devolver la libertad a los prisioneros de los dos lados del Estrecho de Gibraltar. La primera expansión marítima de españoles y portugueses por el Norte de Africa, desde el año de la conquista de Ceuta en 1415 , había seguido los esquemas tradicionales de guerra justa ${ }^{8}$, estableciendo una nueva «marca», cuya tierra de nadie se sitúa ahora en las aguas mediterráneas, que será desde este momento una frontera viva a la vez que olvidada'. En las dos primera décadas del nuevo siglo el corso y el cautiverio seguían siendo armas que eran dominados por los cristianos, un arte de «guerra menor» en el que el balance de apresamiento de hombre y mercadurías era claramente favorable al bando castellano ${ }^{10}$. El mar de Alborán y el Estrecho de Gibraltar eran

3 Para el análisis de este tema sigue siendo muy recomendable la consulta de la obra de George Camamis, Estudios sobre el cautiverio en el Siglo de Oro, Madrid, Gredos, 1977.

4 F. BRAUDEL, La Mediterranée et le monde méditerranéen a l'époque de Philippe It, París, 1949.

5 S. BONO, «Mediterranean Corsairs», History Today, XXXI, 1981, pp. 36-41.

6 Alain MiLHoU, Colón y su mentalidad mesiánica en el ambiente franciscanista español, Valladolid, 1983, en el capitulo III de la segunda parte se analiza el inicio de las nuevas ideas de cruzada interior relacionadas con la llegada de los Trastámara a los diferentes coronas peninsulares.

7 S. Carrasco Urgoiti, El moro de Granada en la literatura española, Madrid, 1956.

8 En el caso portugués resulta especialmente significativo para analizar estos caracteres la consulta de la mejor fuente sobre los progresos de las armas lusitanas en el Atlántico magrebí, como es el Damiao de Goes, Chrónica del Rei Dom Emanuel, Lisboa 1566-1567.

9 A. C. HESs, The forgotten frontier. A history of the Sixteenth Cebtury Ibero-African frontier. Chicago-Londres, 1978.

10 M.A. LADERo-QueSADA, «Castilla, Gibraltar y Berbería (1252-1516)», en Los Mudéjares de Castilla y otros estudios de Historia Medieval andaluza, Granada, 1989, pp. 169-220. 
controlados por los marinos andaluces que actuaban continuamente haciendo entradas para hacer prisioneros en los aduares y lograr mercancías en las cercanas tierras magrebíes, expediciones que se organizaban de manera autónoma y sin contar con el apoyo directo del poder real, como así mismo ocurre con las primeras conquistas hispanas en este territorio a finales del siglo XV. Las pequeñas ciudades magrebíes que se dedicaban a la práctica de esta actividad fueron rápidamente reducidas por la superioridad armamentística y logística de las armadas cristianas antes de la llegada del Emperador a las tierras peninsulares, como pone de manifiesto la conquista de Orán por el Cardenal Cisneros y el control de la mayor parte de los promontorios rocosos y las urbes que daban protección a estos navegantes ocasionales por el Conde Pedro de Navarro $^{11}$. Después de estas empresas sólo queda el reino de Túnez como el gran foco de corsarismo islámico del Mediterráneo ${ }^{12}$ y algunas pequeñas ciudades en el Atlántico que realizan esporádicas incursiones, que se relacionan más con la vida de subsistencia de una frontera que con la guerra abierta entre las dos orillas del Mediterráneo.

La conquista de la isla de Rodas, con la consiguiente expulsión de los caballeros de la Orden de San Juan de Jerusalén que se instalarán bajo la protección imperial en la islas de Malta y Gozo y en Tripol de Bebería (Trípoli), y la llegada de los corsarios turcos de Levante a Poniente van a cambiar radicalmente el panorama del Mediterráneo occidental justo en los años en los que Carlos V pisa las tierras hispanas. El intento de conquistar la ciudad de Argel, urbe de segunda fila en la vida mediterránea hasta ese momento y perfectamente controlada por la pequeña guarnición castellana instalada en un islote situado enfrente de las murallas marítimas, permite a los hermanos Barbarroja contar con un gran número de cautivos de procedencia española e italiana, tantos que la biografía otomana oficial de estos gobernantes refiere que los «reyes de Argel» no saben lo que hacer con ellos ${ }^{13}$, por lo que tienen que idear cárceles especiales bajo tierra que reciben el nombre de baños. El cautiverio moderno en el Mediterráneo es considerado por los propios españoles como un invento de los corsarios Barbaroja, hombres a los que se debe el aumento del

1 M. García-ARenal y M. A. DE Bunes, Los españoles y el Norte de Africa. Siglos XV-XVII, Madrid 1992, pp. 57-101.

12 Sobre la importancia de la ciudad de Túnez en el corso medieval y como se practica esta actividad en esta época sigue siendo muy útil la lectura de la crónica de Pero Niño, El Victorial, Madrid, 1994.

13 Las repetidas derrotas de los españoles ante las murallas de la ciudad de Argel supone que el número de cautivos fuera creciendo muy rápidamente, llegando a haber más cristianos prisioneros que ciudadanos islámicos en los primeros años de la dominación del puerto por los hermanos Barbarroja, según informaciones de las fuentes otomanas, M.A. BUNES, E. SOLA, Vida e historia de Hayreddin. llamado Barbarroja, Gazavat Hayreddin Barbaros Pacha, Granada 1997.

Proyección intemacional de la iglesia hispana Hispania Sacra 51 (1999) 
número y las especiales características que va a tener de nuevo la «privación de la libertad» de los cristianos entre los otomanos ${ }^{14}$. Con independencia de quien sea el impulsor de la nueva dinámica bélica del Mediterráneo occidental, tema que no es objeto de nuestro presente trabajo, en la España de la primera mitad del siglo XVI se tiene claro que la llegada de estos vagabundos del mar, como han sido definidos los fundadores de las Regencias Berberiscas, cambia radicalmente el mundo del cautiverio en el occidente cristiano, e incluso en la mentalidad colectiva de la sociedad y de sus príncipes:

\begin{abstract}
«Estimó el Emperador mucho dar libertad a 15.000 cristianos de todas \{las \} naciones que había en poder de Barbarroja y de otros turcos y moros como principal bien de la victoria. Ca por estorbar el cautiverio de cristianos fue a destruir los corsarios, los cuales se mantienen con la venta o rescate de los que cautivan, antes no serían corsarios sino por cautivar hombres. Opiniones, y aún de quien podría dar por ley si no fuese contra la caridad, que no se redimiese nadie diciendo que tampoco se cautivara. Pero como sea una de las siete obras de misericordia es tan buena la redención como es mala la cautividad. Asimismo fuera de que no habría tantos corsarios ni tantos cautivos, ni daríamos nuestros dineros contra nosotros, no renegarían tantos como reniegan, que es lo peor de iodo. Dicen los historiadores de turcos que no puede ninguno tomarse turco, mayormente si es judio, sin primero bautizarse, comer tocino y hacer otras cosas de cristianos. Antiguamente, según la Siete Partidas, podíamos matar los cautivos en guerra de otra ley y porque hacían otro tanto los moros, y porque no lo biciesen se tenía grandísimo cuidadio de redimir los cristianos. Ca escogían mucho afinadamente para la edención hombres buenos que lamaban alfaqueques, los cuales habían de ser de buen linaje afamado, no pobres ni codiciosos, esforzados, verdaderos, piadosos, que supiesen arábigo. Juraba el mismo y otros 12 hombres de bien en los evangelios o en manos del rey o consejo que lo elegía y enviaba que tenía todas aquellas partes y virtudes. $Y$, con tanto, le daban carta patente del oficio y un pendoncillo con las armas reales y los dineros de la redención, ora fuese de mandas, ora fiese de demandas, ora de la hacienda propia del cautivo y aún también los bienes de los que muriesen cautivos por falta de los no redimir quien era obligado como hijo a padre, amo a criado. Empero se ha perdido tan buena costumbre o por acabarse la guerra de moros o por pasar el cargo de la redención a los frailes de la Merced, que ha $\mathbf{3 6 0}$ años que comenzó. A los cuales se acude con las limosnas y demandas obispado por obispado, como desde Osma a la Merced de Soria. Y ellos, tomando el quinto de todas, sacan de tres en tres años, que hacen capítulo general, o cuando hay manera los cautivos que pueden. También andan hombres particulares sacando cautivos por vía de contratación y aún por caridad, como fue Contreras, clérigo santo que por tal le hizo el Emperador obispo de Guadix y por tal le tuvieron en Sevilla donde murió. Es gran cosa en España la redención de los cautivos, aún por sólo el duque de Escalona que daba 5.000 escudos cada año» 15 .
\end{abstract}

14 «porque hasta el tiempo de este tirano \{Hayreddin Barbarroja\}, no había crecido el número de los cautivos», Gabriel Gómez de Losada, Escuela de trabajos, en quatro libros dividida: Primero, del cautiverio más cruel y tirano, ... Madri, Juan de Paredes, 1670, p. 179.

is F. LÓPEZ DE GÓMARA, Compendio de lo que trata ........ en el libro que hizo de las guerras de mar de sus tiempos, Biblioteca Nacional de Madrid, Mss, $\mathrm{n}^{\circ} 17498$. 
Desde el establecimiento de las repúblicas corsarias en el Norte de Africa, en alguna manera dependiendo de la Sublime Puerta después de haber matado a Oruc Barbarroja los soldados de la guarnición de Orán, el número de cautivos fue aumentando espectacularmente hasta situarse a principios del siglo XVII, época de mayor explendor del corso musulmán en el Mediterráneo occidental, en 25.000 personas para Argel, según las cifras dadas por Diego de Haedo ${ }^{16}$ y el padre Dan ${ }^{17}$, Túnez con unos 15.000 y Trípoli con 4 o 5.000 cautivos. Salvatore Bono establece que después de 1650, época en la que Francia y Holanda ya han tomado la postura clara de reducir el negativo impacto del corso en el comercio marítimo, las cifras se reducen drásticamente a 8.000 en Argel, 6.000 en Túnez y 1599 en Trípoli, según los datos del censo de 1671. ${ }^{18}$. Ellen G. Friedman establece que el número de cautivos liberados por la Orden trinitaria de España entre 1575 y 1769 es de 10.000 españoles ${ }^{19}$, cifra que sería mucho mayor si pudiéramos computar los rescates de otras ordenes religiosas (mercedarios, franciscanos y jesuitas), los realizados por particulares, los cortados, los libertos por musulmanes y los que logran huir por algún tipo de procedimiento.

La extensión del cautiverio en el Mediterráneo genera una sensación de continua preocupación en la sociedad española del momento, que se ve reflejada en la importancia que adquieren las órdenes redentoras y en el dinero que se dedican en los testamentos de los nobles y de los propios reyes para rescatar cautivos. Por citar sólo dos pequeños ejemplos, Carlos V dejará una importante suma para sacar de los baños a soldados imperiales cautivos en Berbería, mientras que Felipe II pide a sus descendientes que liberen a sus súbditos retenidos en Estambul, siendo la inspiración de ambas claúsulas testamentarias la de realizar obras de caridad y no remediar sus respectivos fracasos en la lucha contra el corsarismo islámica en el occidente mediterráneo. En alguna manera, estamos ante un fenómeno completamente nuevo, lo que conlleva el desconcierto y la preocupación de los habitantes de la Península. El cautiverio, el corso y las «razzias» hasta este momento estaban asociadas a la guerra, más o menos declarada, entre cristianos y musulmanes en Al-Andalus y en los territorios magrebíes. $\mathrm{El}$ nacimiento de las repúblicas corsarias bajo protección otomana supone que el corso se convierta en una actividad económica que necesita lograr un número de cautivos y de mercadurías constantes para mantener las bases económicas y sociales de las ciudades dedicadas casi exclusi-

16 D. DE HAEDO, Topografía e Historia General de Argel, Valladolid 1612, Edición de Y, Bauer Landauer, Madrid, Sociedad de Bibliófilos espafioles, Madrid 1927, 3 vol.

17 P. DAN, Histoire de Barbarie et de ses corsaires divisée en six livres, où il est traité de leur gouvernement, de leurs moeurs, de leurs cruántés, de leurs brigandages, de leurs sortilêges et de plusiers autres particularités remarquables, ... París, 1552.

18 S. BONO. Ibidem, pp. 36-41.

19 E. G. FRIEDMAN, Spanish captives in North Africa in the early Modern Age, Wisconsin, 1983.

Proyección internacional de la iglesia hispana

Hispania Sacra 51 (1999) 
vamente al desarrollo de esta actividad. Evidentemente el Estrecho de Gibraltar se convierte en la frontera entre españoles y musulmanes después de la conquista del reino de Granada, y así se mantiene hasta la llegada de los corsarios al Magreb oriental, pero después de esta fecha este limes se transforma en una tierra de nadie muy activo y dinámico, lo que supone que nos encontramos ante una variación con respecto a periodos anteriores. La alianza que realiza Francisco I de Francia con Solimán el Magnífico, y en especial con Hayreddin Barbarroja, supone que se generalice la idea entre los españoles de que el corso musulmán desde 1520 se desarrolle casi exclusivamente contra los súbditos de la Monarquía Hispánica, lo que genera la sensación en España de que arraez musulmán es sinónimo de navegante musulmán que lucha para atacar a los intereses y los súbditos de los Austrias. Además del papel de las embarcaciones francesas colaborando con las flotas corsarias y las armadas oficiales que reconocen la soberanía absoluta de la Sublime Puerta, según avanza el siglo se adhieren nuevos navegantes de otros pabellones a la vida mediterránea. Holandeses e ingleses, bien sea colaborando con los argelinos y marroquíes o bien aisladamente, siguen utilizando el corso y los ataques a las costas de la Monarquía Hispánica para desestabilizar la relación de fuerzas en la lucha en Europa, lo que supone que se generalice la sensación de ataque continuado contra la corona y sus súbditos. El corso, por lo tanto, está representando un sistema económico perfectamente desarrollado, cuestión que estaba más difuminada en vida de frontera de la Hispania medieval, además de una forma de antagonismo político y de lucha por la hegemonia, lo que supone que sea un fenómeno mucho más complejo que el que existía en la época en la que combatían las mesnadas castellanas y aragonesas contra los andalusíes.

De la lectura de la documentación española, bien sea desde la perspectiva de los acontecimientos políticos como desde la propia vida de los cautivos, guerra-corso-cautiverio se relacionan sistemáticamente con una cuestión bilateral entre españoles y otomanos, obviando las consecuencias que tienen las acciones corsarias en Italia o en la costa dálmata. Este proceso de la vida del mediterráneo, perfectamente detectable también por la consulta de la documentación de otros países ribereños del mar, conlleva que todos los sucesos que acaecen a lo largo de los siglos XVI y XVII sean vividos siempre desde la visión de la personificación del conflicto en intereses nacionales. De hecho, los cautivos hispanos legan a la convicción de que los habitantes de la Península son el objetivo prioritario del apresamiento de hombres en el Mediterráneo y los que, según sus testimonios, los más valorados en las almonedas de venta: «Que para que tenga valor, aunque no lo sea, le hacen decir que es español»"

20 M. ZÛ́̃̇(A (OF), Descriptio y Republica de la Ciudad de Argel compuesta por Fr, -.-.-... de la Horden de San Francisco de la provincia de Santiago, BNM. Mss 29075, fol. 40v. 
Según esta visión del problema Barbarroja o Dragut sólo están en este mar para cautivar españoles, sus principales víctimas, desvirtuación de la realidad mediterránea que se mantiene incluso en estudios recientes. El cautivo tiende a unirse durante la privación de libertad con los de su misma nación e idioma, buscar el apoyo de los renegados de su misma procedencia e, incluso, formar cuadrillas compuestas por individuos del mismo origen regional o regnícola, por lo que tienden a vivir dentro de los límites de lo cercano.

La vida en el mar adquiere en estas centurias unos tintes de peligro y de atención constante, a lo que hay que añadir que la navegación siempre fue un arte no muy bien considerado en la mentalidad de la época: «La mar no es tan bien acondicionada para que nadie ose entrar en ella por voluntad sino por necesidad, porque el hombre que navega, si no es por descargo de su conciencia, o por defender su honra, o por amparar la vida, digo y afirmo que el tal o es necio, o está aborrido, o le pueden atar por locos ${ }^{21}$.

En los primeros años del siglo XVI la guerra por mar era una cuestión de segunda consideración. La colaboración de los moriscos en los asaltos y ataques a las costas españolas supone que el peligro del apresamiento se lleve también a todas las fachadas marítimas de la Península, circunstancia que generaliza el miedo y la presión a las autoridades competentes para que atajen este problema. Los sistemas de defensa de costa que se realizan a lo largo de todas las posesiones mediterráneas de la Monarquía Hispánica no resultan demasiado efectivos ante el conocimiento del territorio y de las costumbres de los atalayadores por los corsarios musulmanes, especializados cada uno de los arraeces en zonas muy concretas de la costa, y que cuentan con informantes de diversa índole dentro de los límites de la Península y del resto de las posesiones de la Monarquía. El resultado final de esta dinámica que importan a poniente los corsarios de levante es que se trastoque la vida de un gran número de personas desde, los marinos que surcan sus aguas hasta los militares que están presentes en las diferentes empresas africanas de Carlos V, Felipe II, Sebastián de Portugal y Felipe III, épocas en las que aumenta considerablemente el número de personas apresadas, o de simples pobladores de ciudades y pueblos cercanos a la costa.

El apresamiento de algún personaje de cierta importancia y alcurnia depara que podamos reconstruir los sufrimientos que padece la familia en esta dolosa realidad de la España del Siglo de Oro. El mundo del cautivo y del cautiverio genera desde historias encomiables y dignas de admiracion, tanto desde el punto de vista religiosos como desde el humano, hasta las reacciones propias de la picaresca, como se encargan de recrear los literatos que escriben novelas

21 A. DE GUfVARA, Arte de marear, Valladolid, 1539.

Proyección internacional de la iglesia hispana Hispania Sacra 51 (1999) 
del género. El apresamiento del señor de la villas de Parcent y Murla permite introducirnos en los cambios vitales que genera la acción de los corsarios argelinos en la vida de las personas afectadas:

Haydin Cachidiáblo alzó banderas de paz luego que metió en sus fustas la presa y hombres sobredichos, y así trató el rescate de Pedro Perandreo en 11.000 escudos. Y mientras fueron por los dineros a Valencia llegaron cuatro fustas de Argel a decir a Cachidiáblo como Rodrigo de Portuondo le andaba buscando con la armada española, por eso que se guardase de él. Y por tanto se partió de allí sin rescatar a Pedro Perandreo y lo llevó a Argel donde lo tuvo Barbarroja por cautivo, aunque sin premia. De aquí se requecrieron mil trabajos con grandes gastos a él y a su mujer y hijos, porque se rescató cuatro veces sin ser rescatado ninguna por engaño de uno que fue a Argel a rescatarle; ca rescató a otros por codicia dejando a él bien que su pago llevó. Estuvo en Argel Perandreo 5 años o 6 en cautiverio y llevóle Barbarroja consigo cuando se fue a Constantinopla, según después diremos. Margarita de Roda, que sentía mucho la prisión y ausencia de su marido, envió a su hijo Pedro de Roda a la guerra de Túnez a servir al Emperador y a procurar algún turco o moro para trocar con su padre, mas como no lo pudo haber acordó ir el mismo Pedro de Roda con crédito de mercaderes de Flandes y de allí a Venecia a redimir a su padre o pasar a Constantinopla. Así que hubo en Venecia un salvoconducto de Barbarroja, cual yo ví, por medio de Jorge Corregia, mercader caudaloso que residía en Constantinopla, con el cual y con cédulas de cambio se fue a Ragusa. Y aún iba determinado a quedar por el padre cuando los dineros que llevaba en crédito no bastasen. Mas estando allí le aconsejó Marni de Zamany, caballero del hábito de Santiago, que no pasase a Constantinopla en aquel tiempo por las guerras que había entre venecianos y turcos y porque Barbarroja venía con 80 velas a estos mares con temor de la grande armada en que fue a Argel el Emperador. De suerte que hibernó en Ragusa y se volvió a Venecia donde hubo cartas de Renata, duquesa de Ferrara, para el capitán Polín, embajador al turco por el rey de Francia, y favor de don Diego Hurtado de Mendoza, embajador allí, sobre el rescate de su padre, que se concluyó en 5.000 escudos por medio de mosen Polín, embajador de Francia. Pero aún este concierto no tuvo efecto porque se vino Barbarroja a Tolon, y con él Polín. Fuélos a buscar y tuvo en Génova cartas de Constantinopla como era muerto su padre , y otro día otras de Valencia como había fallecido su madre. Con estas nuevas tan llorosas se vino a Valencia y hallo muerto a su hermano mayor, por do heredó la varonía de Parcent. Hizo en memoria de lo que tengo dicho dos cuadros de mármol con sendas cabezas, una de Pedro Perandreo y otra de Margarita de Roda, y púsolos en san nicolás con dos estrambotes que compuso, los cuales dicen así:

Margarita de Roda me llamaron Nacida en Zaragoza de Aragón Los turcos mi marido me llevaron Quince años ha, que lloró su prisión Saetas de dolor me traspasaron, Çinco, por hijos, çinco, el corazón
No te duelas mujer, vete al reposo que dura para siempre sin afán. Pedro Perandreo fui, tu amado esposo Los turcos más de mí no gozarán Tras ti me voy, de verte deseoso y este deseo no me estorbarán 
La muerte al fin me saca de estas penas Mas ay!, mi marido está en cadenas.
Que en este punto yo muero por verte Oh muy cortés y comedida muerte 22 .

Los duelos y quebrantos que se producen en el entomo familiar del cautivo va a depender directamente de la condición social y de las circunstancias del apresamiento. Además de los desvelos de la familia de Miguel de Cervantes, documentación que se conserva mayoritariamente en el Archivo del Reino de Valencia y que ha sido publicada fragmentariamente desde principios de siglo, resulta especialmente interesante la preocupación que se despiertan por los soldados españoles capturados en la fortaleza de Castilnovo. El Emperador intentó por todos los medios liberar a los militares que había defendido tan esforzada como desesperadamente las murallas de los castillos del Adriático, por lo que se encomendó a personas que informaran sobre el lugar y los patrones de cada uno de los apresados por Barbarroja, siendo muy celebrado la huída de un grupo númeroso de ellos de Estambul cuando logran capturar dos embarcaciones y realizar el viaje por mar desde la ciudad del Mármara hasta Sicilia ${ }^{23}$. Estos casos resultan bastante excepcionales y tienen que ver con el sentido del compromiso que adquiere el gobernante con los soldados que han defendido en nombre de la Monarquía Hispánica con especial valentía. Felipe II también encargará a factores para liberar a los cautivos españoles, portugueses e irlandeses apresados por Ahmad al-Mansur en Alcazarquivir ${ }^{24}$. El Conde Duque de Olivares realizará una acción parecida a la de Carlos $\mathrm{V}$ con los cautivos de Fuenterrabía que estaban en Argel para agradecer y premiar a la ciudad por la defensa de la fortaleza ante la invasión de las tropas francesas.

Los únicos argumentos que poseemos para referir las reacciones de los españoles apresados por los corsarios berberiscos proceden de los textos de los rescatadores y de otras ordenes religiosas, así como de las propias autobiografías y memorias de hombres que padecieron tal trance, razones que explican que las noticias sobre los apresamientos se refieren más a las circunstancias de los combates navales o al asalto de las poblaciones afectadas. Este tipo de textos son muy cautos al referir los comportamientos personales de cada uno de los afectados por el apresamiento. Las historias de cautivos, como afirma Miguel de Cervantes, siempre terminan mal por narrar una continua vida de penalidades y sufrimientos que comienzan por el propio apresamiento:

22 F. LÓPEZ DE GÓMARA, Ibidem, fol. 24 r. y v.

23 Relación del salvamento y libertad de varios españoles que estaban cautivos de los turcos en el año de 1545, Real Academia de la Historia, 9/7500, fols. 44r.-45v.

24 Gracias a esta misión contamos con el excelente relato de Diego Torres, Relación del origen y sucesos de los Xarifes y del estado de los reinos de Marruecos, Fez y Tarudente, edición de Mercedes García-Arenal, Madrid, 1980.

Proyección internacional de la iglesia hispana

Hispania Sacra 51 (1999) 
«Al fin, al cabo de más de veinte días de embarcación partimos del puerto de Málaga con viento favorable, y a dos días de navegación para Orán calmó el viento a vista de Berbería, cerca del cabo de Tres Forcas, de donde salieron ocho galeotas grandes de Argel, cuyo capitán era Arnaut Mamí, renegado albanés. Y así como el patrón de nuestro navío descubrió bajeles de remo, dijo:

-Perdidos somos.

Y comenzó a llorar, ayudándoles todos, y tres mujeres que iban en el navío. Yo estaba aturdido con la enfermedad y, con los llantos y lástimas que todos hacían, milagrosamente se me quitó el mal y me dio ganas de comer, y de contado me comí medio pan que me hallé a la mano y me alenté, y lo que a los demás sirvío de penas, fue para mí de salud con el gran susto que recibí. Luego llegaron las galeotas y, cercando el navío, le tiraron una gran ruciada de flechas diciendo: «iAmaina canalla!».

Yo, que no había visto semejantes cosas, viendo las galeotas con las palamentas y árboles y antenas, popas y proas, todo de colores y tantos turcos con arcos y flechas, y tantos cautivos en cueros, asidos a el remo, me quedé absorto, pareciéndome otro nuevo mundo. Luego abordaron con el navío y con nuestra propia barca pasaron la gente a sus galeotas» 25

El mayor número de las noticias que tenemos sobre las reacciones de los españoles que van a ser apresados suelen ser de semejante jaez. El protagonista del relato demuestra su asombro y su sobresalto por la dura vida en la que es introducido contra su voluntad, conservando la calma por arrogancia o por ignorancia, como sería el caso de la cita anteriormente referida, o considerando que está siendo sometida a una prueba para demostrar su fortaleza. Todos estos episodios se desarrollan en medio de un mar de confusión y lágrimas ajenas a los sentimientos de los protagonistas de los relatos novelados o de los manuscritos que refieren estos sucesos:

«... no pasaron tres horas que no vieron hacia la parte de tierra (que ellos se babian hecho al largo del mar) una galeota de turcos, y aunque los marineros hacian la fuerza que podían por llegar a tierra, más priesa se dió la galeota, y llegando a tiro de arcabuz, arrojaron tantas balas, que tuvieron por bien de amainar luego, y entraron muchos turcos en la fragata... Era necesario que el padre acudiera a consolar sus compañeros, que perdían la paciencia, a confesar algunos heridos que estaban a la muerte, consolar y acudir a otros que le pedían pan y agua llorando, que parecían como si él tuviera allí una gran dispensa, y fuera su padre o madre, y no cautivo como ellos, a reprimir algunos que blasfemaban por verse esclavos, a reprehender a otros que concedían ya con los turcos en tratos nefandos, principalmente algunos mozos desbarbados, que juntamente fueron cautivos; animar a otros que estaban ya tentados y trataban ya renegar la fe, con estas y otras muchas cosas a este tono.» ${ }^{26}$

25 D. GALÁN ESCOBAR, Relación del cautiverio y liberias de Diego Galán, natural de la Villa de Consuegra y Vecino de la ciudad de Toledo, Biblioteca del Real Monasterio de El Escorial, Ms. I,III,28, Edición de M.A. de BUNES y M. BARCHINo, Toledo (En Prensa), p. 42.

26 J. GRAClÁN DE LA MADRE DE DIOS, Los trabajos y vida del padre maestro Gracián, que salió de Madrid expulso de los Descalzos, Valladolid, 1619, editado en la Biblioteca de Autores Españoles, en Escritos de Santa Teresa, II, Tomo LV, p.457. 
La mayor parte de los textos que podemos referir se refieren a españoles que lograron soportar el trance del cautiverio, razón por la que establecen la fortaleza de sus convicciones religiosas y vitales ante tal suceso, e incluso se alegran de las penalidades sufridas por los cambios y novedades que depara tal episodio para su formación personal:

«Desta resolución consideré cuando tuve más uso de razón que no fue voluntad de Dios que aquel caballero diese licencia, por tener determinado Nuestro Señor lo que había de padecer entre infieles y las penas que mis padres habían de tener en todo el tiempo que estuve cautivo hasta que me vieron entrar por sus puertas. Son secretos suyos para dar en qué merecer sus criaturas, y cuando nos parece son castigos, son misericordias. $Y$ yo por tales las tuve, pues hubiera sido peor que el tiempo que estuve cautivo y dominado lo hubiera malgastado por acá, y es de creerme que lo estimo en tanto que si fuera posible valorarlo a dinero no lo diera por veinte mil escudos. Sólo dije que la mayor pena que tuve y hoy dura es mi corazón son las grandes penas que mis padres tuvieron por ocasión mía” ${ }^{27}$.

La realidad de cautiverio no es ni un elemento de conformación de la personalidad, tal como refiere Diego Galán en la cita anterior ni tampoco una experiencia de corte místico como afirma Jerónimo Gracián. Este religioso, confesor de Santa Teresa de Jesús y reformador de su orden religiosa a principios del siglo XVII, tiende a relacionar sus penalidades vitales con su propia trayectoria mística:

\footnotetext{
«Hame dicho que en toda su vida se vió con mayor contento, y mayor paz: el bizcocho le sabía más que almendras, el agua le satisfacía más que malvasía, y otro día que entró en la galera, usando las mañas de los esclavos, tomó a vuelta de cabeza de una cosa o será de un turco, dos cabezas de ajos, que conservaba para ir comiendo poco a poco con el bizcocho negro; y demás del alegría de padecer en poder de enemigos en la fe, dábale contento: vióse libre de las perpeglidades de pensamientos por do había pasado en el negocio de su estado, y como quien ha llegado ya a término de trabajos, que podía olvidar los enredos de atrás y disponerse para vivir en Cristo, y morir por El. Parece que se le mudó el corazón y abrió el cielo, y llegó a cumbre de paz y seguridad» ${ }^{28}$.
}

Todas estas reflexiones son pensamientos realizados cuando el cautiverio es un elemento del pasado, cuando uno se ha alejado del agobiante ambiente del baño, de la necesidad de tener que robar para poder comer o estar siempre usando mañas para lograr padecer con menos rigor la dura vida de la privación de la libertad.

27 D. GALÁN, Ibidem, p. 38.

28 J. GRACIÁN DE LA MADRE DE DIOS, Ibidem, p. 458.

Proyección intemacional de la iglesia hispana

Hispania Sacra 51 (1999) 


\begin{abstract}
«Hallaron los esclavos metidos en una cárcel o encierto que llaman canuto, distribuídos en bovedas subterráneas y profundas, húmedas, desiguales y sin luz, sólo a propósito para trabajosa habitación de bestias fieras. Allí, con gran dolor de sus corazones, vieron a unos comidos de animales inmundos, a otros heridos y desollados a palos; a unos hinchados de pies y manos de las humedades y de los grillos; a otros débiles, hambrientos y enfermos, sin esperanza de médicos o cirujanos. Uno suspiraba, otro pedía misericordia; uno daba gracias de la ocasión para confesar sus culpas, otro alababa a María Santísima por haberles enviado religiosos redentores que se compadeciesen de su miseria y, finalmente, todos angustiados lloraban una crueldad que no se cuenta semejante en las cautividades de Túnez y Argel» 29
\end{abstract}

Además de los padecimientos y rigores de todo tipo que tiene que llevar en su nueva vida, el español que ha sido cautivado, lo que no entienden en ningún momento la organización social en la que se ven inmersos en contra de su voluntad. Las sociedades nuevas, como se pueden definir el mundo de las ciudades que nacen en el siglo XVI en el Norte de Africa, trastocan completamente el orden de valores tadicionales en los que han sido educados los españoles:

«MATA.- ¿Pues qué más harían los gitanos?

PEDRO.- Tan hábiles son los esclabos como ellos, porque tienen el mesmo maestro, que es la necesidad, enemiga de la virtud» ${ }^{30}$.

Además de cambios vitales evidentes, la privación de la libertad supone la pérdida de los valores y las maneras religiosas, llegando a considerar algunos rescatadores de cautivos que la mayor parte de los retenidos por los berberiscos se convierten en agnósticos, además de caer en un gran número de errores doctrinales y creenciales. Desde este punto de vista, el cautiverio es doloso por los sufrimientos físicos y la pérdida de la libertad, así como por la inmersión en un universo cultural y humano regido por normas divergentes a las sociedades tradicionales europeas:

«Porque acá halla otro Dios, otra ley, otros templos, otros sacerdotes, otras ceremonias, otras costumbres, otro hablar, otro escribir al revés, otro comer en el suelo, otro sentarse en cuquillas, otro talle, otro vestido y otro trato y aun otro vivir, en todo muy diferentes. Acá no hay justicia, sino fuerza; no dar, sino robar; no templanza alguna, sino todo crápula y lujuria; no fortaleza, sino temeridad; no verdad, sino mentira; no amistad, sino cada uno para sí; no lealtad, sino engañarse unos a otros; finalmente, acá no hay estados, no puntos, no primores, no dignidades, no bríos, no cortesías, no crianza. Acá la libertad se convierte en esclavitud, la honra en afrenta, la gloria en abatimiento,

${ }^{29}$ Breve noticia de la redención de cautivos que de especial orden de S.M. se ha ejecutado en la ciudad de Tánger en I64I, s.l., s.i., s.a.

30 Viaje de Turquía, Edición de García Salinero, Madrid, Cátedra, 1980, p. 192 
la nobleza en vileza, el valor en vituperio, la grandeza en poquedad y aun las virtudes todas en vicios" ${ }^{31}$

El cautiverio, según esta visión, supone que se trastoque casi completamente el orden establecido, con la consiguiente destrucción moral y psicológica de las personas que padecen tal trance:

\begin{abstract}
«Conocí en Argel el desprecio grande que tiene el cautiverio en muchas cosas que experimenté. Allí hay algunos cristianos francos, que assi se llaman los que ya están libres, y se han rescatado, y muchos Mercaderes que van a comerciar, aunque conozcan al cautivo, sus prendas y méritos le vuelven el rostro, ni le hablan, ni comunican; como si el desventurado tuviera la culpa de su mala fortuna, y como si fuera un monstruo y indigno de parecer entre hombres: y lo que más es, que el mismo parece se olvida, ni mira por sí, ni sabe que es honra ni punto de ella, ni primor, se abate, se apoca y envilece, y el desdichado estado le obliga a hacer algunas cosas que se afrentaran los más bajos y despreciados del mundo ${ }^{32}$.»
\end{abstract}

Llegan a la convicción de que la extensión del cautiverio lo único que depara son males para la Monarquía y sus súbditos. El dinero entregado para los rescates va empobreciendo al estado y los españoles que son apresados caen en todos los vicios y los errores, generalizándose el mal entre ellos:

«\{prostitutas\}son las más que se cautivan de las que llevan los soldados en los navíos, y quando las apressan los Moros, van a parar a Argel, y si entre Cristianos son malas, peores son entre Moros» ${ }^{33}$.

La vida del Mediterráneo del Siglo de Oro, como se pone de manifiesto en el trabajo del matrimonio Bennassar ${ }^{34}$, es el de la creación de un universo humano y vital que rompe muchas de las características con las que ha sido definida la sociedad española, y por extensión la de los países ribereños del mar, durante estas centurias. El corso fue siempre un arma política utilizada con cierta habilidad por los diferentes gobernantes que, sin embargo, era prácticado en su mayor parte por antiguos cautivos que reniegan de sus creencias para lograr una vida mejor: «sono y vero protagonisti de lla guerra corsara e constituiscono l'elemento principale de quel flusso continuo de relazioni fra gli opposti mondi... La storia dei corsari è, in gran parte, la storia dei rinnega-

31 D. DE HAEDO, Ibidem, tomo II, p. 23.

32 G. GOMEZ DE LOSADA, Escuela de trabajos, ..., Madrid 1670, p. 23.

33 G. GOMEZ DE LOSADA, Respondese a un memorial que se dio a su Magestad sobre el rescate de los Cortados, niños y mugeres que padescen en la tiranta y cruel Esclavitud de Argel, s-i-,s-a. fol $3 \mathbf{r}$.

34 B. y L. BENNASSAR, Los cristianos de Ala. La fascinante aventura de los renegados, Madrid, 1989

Proyección internacional de la iglesia hispana

Hispania Sacra 51 (1999) 
ti...»35. Este supuesto contrasentido supone que por debajo de los relatos de los cautivos que lograron volver a sus antiguas tierras y escribir relaciones memorables existe toda una serie de realidades intermedias, de creación de un moral de circunstancias que permite sobrevivir en un mundo de misturas y ambigüedades. El análisis de los cautivos como un elemento más de la sociedad espanola, y en general europea al estar inmersos en estas circunstancias hombres de todo el orbe conocido en esas décadas, del momento es un tema que aún no se ha realizado de una manera sistemática por haber primado más los trabajos de corte pietista o tendentes a relacionar la redención con la religiosidad del momento. El cautivo sirve perfectamente a los hombres que están realizando la «guerra en el papel» contra los musulmanes al representar el lado miserable, al mismo tiempo que heroico, de la iglesia sitiada por los enemigos espirituales y temporales, lo que permite a Diego de Haedo escribir un Diálogo de los mártires de Argel $^{36}$ en el mismo tomo que está refiriendo el nacimiento y el primer siglo de vida de la República Berberisca. Este texto se fija más en las muertes y crueldades que padecen los cautivos que en reseñar las auténticas condiciones de vida de los cautivos y los cambios que padecen en sus personas.

El nuevo cautivo no se resigna a su adversa suerte sino que pretende escapar lo más rápidamente posible de su nueva condición vital y social:

«Estos, como se vieron en el vano invierno, comenzaron a tratar de buscar su libertad, que es cosa de esclavos nuevos el buscar novedades y trazas ${ }^{37}$

La vida de cautivos son relatos memorables y edificantes que esconden debajo de las líneas escritas toda una serie de variaciones y combinaciones que se silencian continuamente. Desde los hombres que reniegan para intentar escapar, los que lo hacen para llevar una vida menos rigurosa o por sentirse atraidos por el Islam hasta los religiosos que buscan el martirio en tierra de infieles para alcanzar antes la salvación del cristiano hay una largo trecho en el que nos podemos encontrar un gran número de circunstancias y situaciones, aún no exploradas convenientemente. Ni siquiere la libertad del apresado supone que se olviden las penalidades del pasado ya que no resulta infrecuente noticias de cautivos que al volver a España deciden volver a tierras musulmanas por no poderse integrar nuevamente en su antigua sociedad:

35 S. BONO, I corsari barbareschi, Roma, 1964, pp. 5-6.

36 Este libro de la Topografia e Historia General de Argel ha sido publica recientemente por E. SOlA y J.M. PARREÑo dando la autoría del texto a Antonio de Sosa, Dialogo de los máritires de Argel, Madrid 1990.

37 J. DE PASAMONTE, Vida y tabajos de Jerónimo de Pasamonte, Biblioteca de Autores Españols, XC, p. 16. 


\begin{abstract}
"Yo me bajé tan desconsolado que no lo podńa encarecer, considerando si a un hombre como yo que viene de cautiverio y ha derramado tanta sangre le quitan su sudor iqué harán a los đemás! Juzgué que había más embustes entre cristianos que entre turcos ${ }^{38}$.
\end{abstract}

El tema del cautiverio y de los cautivos no sólo supone entrar a describir las especiales características que tiene la vida en el Mediterráneo en la Edad Moderna, sino que es un elemento esencial para conocer los caracteres globales y generales de la sociedades mediterráneas de estas mismas centurias. La psicología del cautivo es la de un desheredado de la fortuna que tiene que sobrevivir en un mundo hostil y adverso, hostilidad y adversidad que no es imputable únicamente a sus captores. $\mathrm{El}$ tema era materia para que fuera rápidamente asumida por la literatura del momento, tanto la costumbrista como la picaresca, por lo que no es extrañas que algunos de los célebres ampones descritos por la textos del Siglo de Oro tuvieran algo que ver con los cautivos y con el ambiente de los baños y las cârceles norteafricanas y estambuliotas. La reseña literaria de estas figuras resulta, por lo tanto, especialmente atractiva, aunque nunca llega a la crudeza y la diversidad que se encuentra en los innumerables legajos mauscritos que aún quedan por desempolvar sobre este tema en los países del Mediterráneo, comenzando por los archivos españoles.

38 J. DE PASAMONTE, Ibidem, p. 31.

Proyección internacional de la iglesia hispana Hispania Sacra 51 (1999) 